\title{
Framing Crisis Information Systems: The case of WIS
}

\author{
Ted Saarikko \\ Umeå University \\ ted.saarikko@umu.se \\ Kalevi Pessi \\ University of Gothenburg \\ kalevi.pessi@ait.gu.se
}

\author{
Urban Nuldén \\ University of Gothenburg \\ urban.nulden@ait.gu.se
}

\author{
Pär Meiling \\ University of Gothenburg \\ par.meiling@ait.gu.se
}

\begin{abstract}
Relief efforts for natural and societal crises require a multitude of agencies to effectively and efficiently share information and coordinate their efforts. In 2009, The Swedish Civil Contingencies Agency launched a Web-based Information System (WIS) for Information sharing in crisis management. The system has undergone two major revisions and is applied nationwide with the intent of aiding inter-agency coordination. The study draws upon Orlikowski and Gash's notion of technological frames to contrast the perspectives of technology users and technology promoters. The study revealed that both stakeholder groups agree on the potential benefits of the system, but differ in their view on the system itself as well as its application in practice. Furthermore, the study highlights the limitations of dedicated ICT for crisis management as users perceive WIS to be useful in coordinating slow-moving events that involve many different societal actors, yet unwieldy to deploy in a sudden crisis.
\end{abstract}

\section{Introduction}

The summer of 2018 saw most of Europe caught in a severe heat wave for several months, leading to drought that limited supplies of fresh water as well as spawned raging forest fires that caused severe damage to property as well as human casualties [1]. Extant research has highlighted the potential contribution of electronic communication in alerting and involving the public regarding natural disasters or societal crises. Information and Communication technologies (ICT) can be used to create ad-hoc networks using social media [2] as well as support inter-agency coordination and action [3, 4]. The purpose of this paper is to study how ICTs intended to facilitate information sharing on crisis situations are perceived by different stakeholders. We use the term crisis to encompass sudden disasters as well as slowly developing disturbances to societal functions and institutions.

The research purpose is pursued through the qualitative case study of a system for crisis management called Web-based Information System (WIS) currently in use among government agencies on the national, regional and local levels in Sweden. Development and maintenance of WIS is funded and directed by the Swedish Civil Contingencies Agency - the national authority responsible for civil protection and emergency management. The system has been in use for over a decade with two major redesigns since its initial launch - the most recent in 2017. In our study, we have focused on two perspectives: promoters and users. The former perspective is represented by documentation pertaining to purpose, functionality and user guidelines going back to before the system's initial launch as well as interviews with project managers at the Civil Contingencies Agency. The latter perspective is represented through interviews with representatives from ten county administrative boards - government agencies in charge of regional oversight and emergency management. Our research question may be stated as how do stakeholders make sense of shared ICT resources and their role in supporting crisis management? The term stakeholder will be used to refer to the two focal groups of our study: the technology promoters at the Civil Contingencies Agency and the technology users at the county administrative boards.

Whereas other studies [e.g. 4, 5, 6] often present theoretical models on information systems for crisis management, this paper contributes to our understanding of crisis information systems by studying a mature system that has been in use for over a decade. Following the introduction, the paper will review research on ICT-supported sensemaking and introduce technological frames which is used as an analytical 
framework. Chapters 4 and 5 present the research design and findings, respectively. Chapter 6 offers an analysis of the findings which are then discussed in chapter 7 along with suggestions for future research. Chapter 8 summarizes the study's conclusions and limitations.

\section{Related research}

While virtually any Information and Communication technology (ICT) can be leveraged in a crisis [2] much of it remains ad-hoc. The figurative explosion of mobile connectivity in recent years has illustrated that ubiquity does not necessarily equal accuracy as social media may bring us erroneous information $[7,8]$ or tempt us to evaluate sources based on ability to provoke an emotional response rather than factual content [9]. While self-organizing social media networks are largely (or entirely) directed at informing the public, ICTs can also be used by government agencies to organize rescue efforts, e.g. by facilitating a shared situational awareness among crises responders $[3,4]$.

Information exchange is a delicate balance between sharing sufficient information and sharing information within a suitable time frame $[4,10]$. While information exchange can be highly formalized, e.g. using standardized syntaxes and definitions, crises rarely permit such luxuries as they are characterized by unstable and evolving conditions [11]. Wolbers and Boersma [12] have argued that "trading zones" of information exchange are particularly apt for crisis management and incremental establishment and use of Common Operational Pictures (COP) - a type of boundary object that facilitates shared sensemaking in crises or emergencies where multiple parties need to coordinate their efforts [13].

Sensemaking in crises can be facilitated by putting representatives or key personnel from relevant organizations in direct contact with one another. Landgren and Bergstrand [14] describe how collective sensemaking between different government agencies is facilitated via "situation rooms" that provide a venue for interdisciplinary (between professions) and intersubjective (between individuals) assembling of information, monitoring resources in the field, exploring implications of the developing situation, converging on a shared understanding, and (if needed) consolidating the group to handle diverging viewpoints. While extant literature (e.g. [15]) emphasizes conversation and speech as mediums for sensemaking, there is research that highlights the material aspects of sensemaking [16] and the potential role of digital media [17]. That is, people can enact sensemaking and sensegiving via material artefacts such as visual presentation software
[18], white boards [19] or even boundary-spanning artefacts such as drawings or models [20] that can facilitate understanding across different professions or communities.

\section{Technological frames}

The concept of frames can in a broad sense be defined as "a cognitive device that enables individuals to comprehend, understand, and explain the world around them" [21, p. 50]. Orlikowski and Gash studied the different frames held by technologists (i.e. technology advocates) and users in the introduction of a software client for e-mail. Based on their study, they defined technological frames as a more specific type of frame which describes the "subset of members' organizational frames that concern the assumptions, expectations, and knowledge they use to understand technology in organizations" [22, p. 178]. They relate to our perceptions, assumptions, knowledge and expectations and arise from education, work experience and interactions with different groups [22, 23]. Technological frames possess two main characteristics [21]. First, they facilitate sensemaking by making us notice some factors while missing (or ignoring) others. Second, they are context specific, meaning that the same technology may be interpreted quite differently in disparate settings. As such, frames may be congruent or incongruent. Frame congruence refers to the level of similarity between frames held within groups (e.g. the technology-in-use frame and technology strategy among users) or across different groups (i.e. the technology strategy frame among software users and software creators). As similar perspectives on - and usage of - technology tools is often desirable, congruence in frames can be viewed as a measure of success in information systems implementation [21].

Table 1. Technological frames.

\begin{tabular}{|l|l|l|}
\hline Domain & Description & \multicolumn{2}{|c|}{ Key question } \\
\hline $\begin{array}{l}\text { Nature of } \\
\text { Technology }\end{array}$ & $\begin{array}{l}\text { Understanding of } \\
\text { technologies or artefacts } \\
\text { and their possibilities }\end{array}$ & "What is it?" \\
\hline $\begin{array}{l}\text { Technology } \\
\text { Strategy }\end{array}$ & $\begin{array}{l}\text { View on how } \\
\text { technology can be } \\
\text { applied to further the } \\
\text { organization's agenda or } \\
\text { interests }\end{array}$ & $\begin{array}{l}\text { "Why should } \\
\text { we use it?" }\end{array}$ \\
\hline $\begin{array}{l}\text { Technology in } \\
\text { Use }\end{array}$ & $\begin{array}{l}\text { technology is used (or } \\
\text { will be used) and the } \\
\text { consequences that may } \\
\text { bring for day-to-day } \\
\text { tasks }\end{array}$ & "How do we \\
\hline
\end{tabular}


Although the application and nomenclature of technology frames differ between studies, three frame domains appear to be broadly accepted and applied [23, 24]: frames related to technology features, frames related to organizational applications of technology, and frames related to technology as applied in work practices (see table 1). We will refer to these using the terms originally coined by Orlikowski and Gash: Nature of Technology (NoT), Technology Strategy (TS), and Technology in Use (TiU).

\section{Research design}

This paper features qualitative study [25] of WIS - a web-based system for crisis management and applies technological frames [22] as an analytical framework. Studies using technological frames as an analytical framework have been criticized for focusing on "snapshots" in time rather than studying how frames may change over time [26]. This study mitigates this issue by studying a mature system that has been in use for over a decade - albeit with gradual improvements.

\subsection{Research context}

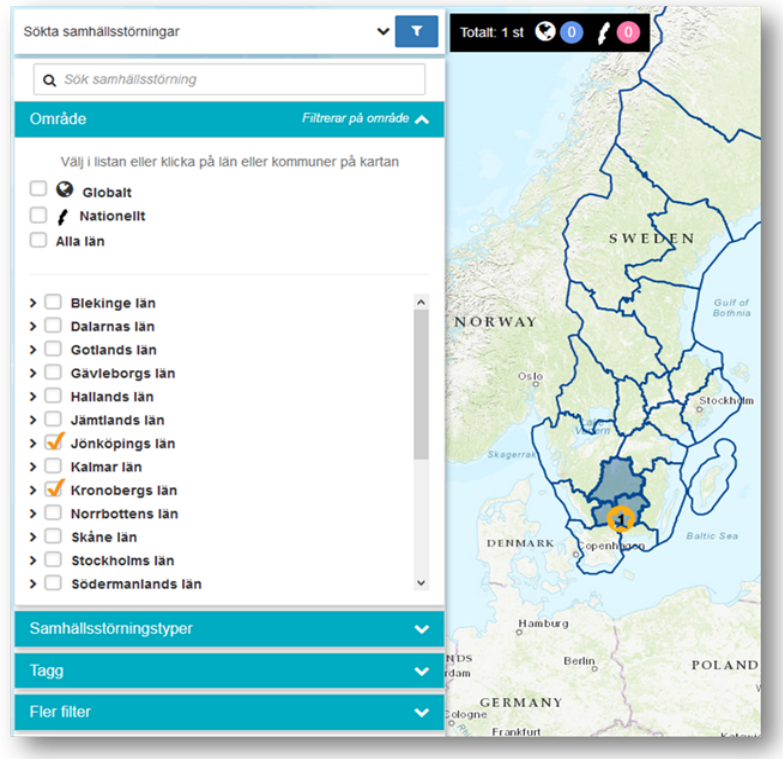

Figure 1. National overview in WIS permits queries by region or type of crisis.

WIS is a national, Internet-based information system created with the intention to facilitate information sharing between entities in the Swedish emergency management structure before, during and after emergencies. Although intended for crisis management, the Civil Contingencies Agency is adamant that WIS is designed to be flexible with regards to situation type, scope and actors involved.

In WIS, the various actors share information with one another via a shared spaces. A space constitutes a workspace that can be linked to a specific region or event where relevant updates are published and different actors can share information. Each actor sets their own access rights and determine who should be authorized to access the information published in their journals and spaces. As WIS is primarily intended to support interaction between actor groups, e.g. national agencies such as law enforcement, regional councils that manage healthcare, and local municipalities, day-to-day accidents that fall within the purview of a single agency (e.g. personal injuries or criminal activity) are typically not fed into WIS unless they somehow affect societal functions (e.g. if authorities have to evacuate a residential area or close down a bridge). Initial development of the system took place during 20042005. WIS has undergone three major iterations of development. The first version to use its current name was launched 2009, the second version was released in spring 2013, and the third version was released in January 2018. Initially, WIS was a system designed for gathering news material where users could create logbooks (or "journals"). As the system has been developed, the purpose and commensurate terminology has shifted towards an information system facilitating sharing among disparate actors, allowing them to create a Common Operating Picture (COP) during a crisis. About 500 actors are connected to WIS with more than 7000 individual users. All Swedish county administrative boards and county councils are affiliated along with 95 percent of Swedish municipalities.

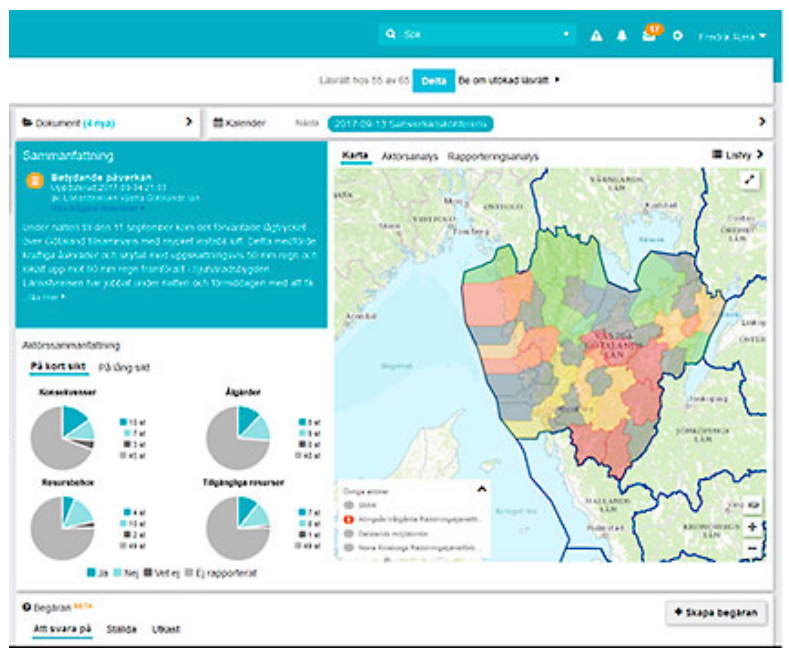

Figure 2. County view with color-coding indicating level of disruption in municipalities. 
The Swedish Civil Contingencies Agency (sv. Myndigheten för samhällsskydd och beredskap, MSB) is the Swedish authority responsible for issues concerning civil protection, public safety, emergency management and civil defense, and it is organized under the Ministry of Justice. MSB works in close cooperation with local municipalities, regional county councils, other authorities, organizations and the private sector to achieve increased safety and security at all levels of society.

County administrative boards constitute the regional government agency in each of the 21 counties of Sweden. They serve under the Swedish national government, and their main responsibilities are to align regional activities with national goals and policies including coordination of local and regional resources in crisis management. Given the responsibility of county administrative boards to supervise regional development and coordinate resources in crisis situations, MSB has identified them as one of the primary stakeholders and "power users" of WIS.

\subsection{Data collection}

Our study addresses two types of stakeholders related to WIS. The first, which we will call technology promoters, captures the views and perspectives held by those that develop and offer the system, i.e. MSB. The second, which we will call technology users, captures the views and perspectives held by those who apply the technology in executing their professional tasks, i.e. civil servants at county administrative boards.

In line with case study methodology [27], we draw upon different information resources pertaining to the object of the study. Data from the promoter side was collected by means of the documentation issued by MSB that describes WIS and offer user guidelines in relation to crisis preparedness and management. The documentation is made up of 10 documents published between 2003 and 2017, encompassing approximately 700 pages. Additionally, two explorative interviews were conducted in person with project managers at MSB. The interviews lasted approximately two hours each and were recorded and transcribed. Data from the user side was collected via 16 structured interviews with civil servants from 10 different county administrative boards. One interview was carried out in person while the remaining 15 were conducted over telephone. These interviews lasted approximately 30 minutes each and were also recorded and transcribed.

Promoter-side interviews preceded user-side interviews and permitted the researchers to explore WIS in terms of development history and underlying motivation. Both respondents are key staff are project managers and manage WIS development. Both promoter interviews were conducted in February 2018. User-side interviews were initiated via an e-mail sent out to all 21 county administrative boards. Ten of the counties responded and offered contact information to one or two suitable contacts that use WIS as part of their job. Despite the structured nature of the interview, respondents were encouraged to provide detailed and elaborate answers. All user interviews were conducted during October 2018.

\subsection{Data analysis}

The analytical approach follows the interpretive methods of research established within information systems research $[28,29]$. That is, the study was aimed at providing an understanding of how information artefacts and information systems interact with - and are interpreted by - their surroundings [30].

While extant studies have shown the merit of applying the technological frames perspective as an analytical framework [23], it is somewhat coarse and subject to individual interpretations. In an effort to mitigate these tendencies, data analysis proceeded in three steps. First, one randomly selected interview transcript was individually read and coded by researchers. Three of the researchers then met and compared how they had coded the transcript. Deviations were highlighted and discussed until a consensus was reached. This first step was iterated four times until a satisfactory inter-coder agreement [31] was achieved. Second, coding of the remaining interviews and documents was divided among all authors. Upon completion, one of the authors documented the efforts using Atlas.Ti coding software in order to facilitate further analysis. Third, all four authors met and collectively reviewed the coded material (i.e. statements from interviews and passages from documents), eventually arriving at three empirically derived themes in each domain (see section 5) which aided the appraisal of frame congruence. The collective approach to coding and analysis serves to minimize personal bias and promotes inter-subjective understanding of the material as well as analytical framework [32].

\section{Findings}

Findings are structured according to the domains outlined in the theoretical framework: Nature of Technology, Technology Strategy and Technology in Use.

\subsection{Nature of Technology}


The promoters of WIS (i.e. MSB) have offered different descriptions of the system over the past 15 years. The original report from 2003 in which a shared, multi-agency system was first proposed emphasizes a journal system that "may be used by municipalities, county administrative boards and other agencies free of charge" if they are somehow involved in crisis management. Other documentation from this period (i.e. mid to late 2000's) describes it as a "Non-hierarchical information tool with logbook-functionality" and there is a strong emphasis on creating - and sharing - a record of past events and activities.

The portrayal of WIS has however shifted as additional functionality was added in the major upgrades of 2013 and 2018. Guidelines from 2017 characterize it as a "national web-based information system developed to facilitate information sharing between actors in relation to crisis management before, during and after a crisis". From a technical standpoint, it is described as a standardized environment with considerable flexibility - including the ability to integrate it with other tools used by local, regional or national government. MSB is responsible for technical maintenance, but emphasizes that it does not manage or moderate the information stored within the system. The user guidelines for WIS clearly states that no individual actor owns a crisis or the associated information. Neither the documentation nor the interviews yielded any particular detail regarding who actually owns the information stored in the system, but it is clearly stated that the system is intended for strictly non-classified or otherwise unrestricted information. While the ambition is for WIS to be used across all levels of government, usage is not mandatory. MSB has funded development since 2009, but done relatively little to promote system adoption. As one of the project managers put it: "Historically, MSB hasn't made a big deal of it, but rather put it out there and said 'there you go - use it'. This has of course brought about a bit of disparity [in usage]."

The user group featured in our study (i.e. civil servants at ten different county administrative boards) described WIS using a variety of terms and expressions: a system for documentation, a system for Common Operating Picture (COP), a system for compiling reports, a system for file sharing, a platform for officers on duty and a space for collaboration. Users generally perceive WIS as a proactive tool where information can be shared in anticipation of an event (e.g. severe weather conditions) as opposed to merely in the wake of an unexpected crisis. Moreover, they describe the system design as generic and able to accommodate different types of content depending on the situation. As such, the system is perceived a bit differently from other tools used by the county administrative boards that usually have more limited scope and clearly defined realm of application, e.g. software for creating customized maps or encrypted equipment used to communicate with law enforcement. Several respondents drew similarities to social media, and expressed that it is "...like a variation of Facebook, but a bit more serious".

The functions most commonly highlighted by users as useful are among the most mature and simple features. First, the journal where staff can report events and the reports properly stored, time-stamped and made available to anyone who has an interest in reading them. Second, one of the main responsibilities of county administrative boards in a crisis is to stay in contact with actors that are impacted or assisting in ameliorating the situation. A system like WIS provides a shared environment where COP and other resources can be made accessible.

One of the main issues brought up was a sense of uncertainty regarding how open the system really is. While it is clear that classified information should not be published here, there is some confusion as to what level of detail is permissible, who is allowed to read information posted in WIS, and the extent of the MSB's role vis-à-vis WIS.

As an antecedent step to theoretical analysis, data was categorized and grouped based on empirically derived themes. We identify three themes related to Nature of Technology: characterization (how the system is conceptualized and described), functionality (the technical features of the system), and openness (what restrictions and degree of freedom that is built into the system).

\subsection{Technology Strategy}

The documents reviewed during the course of the study repeatedly stated that civil society has an obligation to cooperate locally, regionally and nationally as needed in the face of a crisis. WIS was developed to support this aspect of government responsibility and replace manual administrative efforts - or technology-mediated functions divided across multiple systems - with a single, shared system for sharing critical information. Thus, in crisis management, WIS would provide 'one-stop shopping': A single system where actors can share information and stay updated. Moreover, as it is difficult to anticipate the extent and nature of future crises, WIS was designed to support different constellations of stakeholders as required by the particular circumstances of the event.

WIS is intended to provide a secure means to collaborate and exchange information. In this context, secure does not only refer to cryptographic properties, but also to reliability and structure. In practical terms, WIS provides an alternative to information exchange via 
e-mail accounts that are usually tied to individual staff members that may be sick, on holiday, or otherwise unavailable to check their e-mail. In contrast, information posted in WIS is available for anyone at an agency (or region) to read at their leisure.

While users employed a variety of terms to describe WIS (see section 5.1), there was greater coherence in their view on the purpose of the system: they need a computerized system to support their obligations. A system like WIS is of particular importance to county administrative boards as they have a role to supervise regional development and coordinate resource deployment in the event of a crisis. Their role is primarily strategic and they have little in terms of operational capabilities - or as one user put it "we do not have any boots on the ground". One of the main responsibilities of county administrative boards in a crisis is to establish a COP which briefly summarizes the timeline of events, current status, and anticipated developments. As one user put it: "It's great, because it gives everyone the same ability to understand the incident and everyone has the same [COP], or preconditions, and that's where WIS really shines".

WIS also offers two distinct advantages to individual users. First, it reduces the need to participate in all meetings as notes and minutes are easily accessible in a structured manner via WIS, making it considerably easier to catch up in case of absence. Second, the same system features also make it easier to transfer tasks between employees when and if that becomes necessary. Hence, WIS serves to make the crisis management more robust and less dependent on persistent availability of individual staff member.

We identify three themes related to Technology Strategy: scope (the overall aim and purpose of the system), task benefit (how the system contributes to execution of key processes), and user benefit (how the system supports individual employees).

\subsection{Technology in Use}

Despite being in use for a decade (or longer if you include the preceding system launched under a different name), one of the project managers at MSB described that it is only now that WIS is bearing fruit. "[I]t wasn't too many years ago that there were a lot of moaning about 'yet another system.' But in a lot of places I think it's not a matter of discussion. You just get on with a lot of stuff in WIS in sort of...everyday work as well as when [a crisis] occurs. I'd say we're on the verge... sort of at a tipping point."

MSB offers very little centralized governance, but offer advice on good practices. For instance, actors are encouraged to promote familiarity with the system among its users by utilizing it for mundane tasks (e.g. keeping a logbook) wherever possible. Moreover, it is also emphasized that each actor is responsible for training their staff (including replacements) in using WIS. MSB is sometimes asked to provide normative guidelines on how to use the system, but universal rules are difficult to reconcile with regional preconditions and perspectives. Also, the advice offered to users can be somewhat inconsistent. For instance, in order to utilize the potential of WIS, users are encouraged to share information quite liberally. Ideally, they should use the system to monitor situations and share proactively when deemed suitable. At the same time, users are reminded that all information is (legally) public and recommended "not to over-share". To combat some of the confusion, there are plans (as yet unfulfilled) to develop illustrative use cases that can be disseminated to actors, suggesting good practices in WIS.

Recent events, notably the European migrant crisis of 2015 and the drought and subsequent fires of 2018, have provided a clear sense of the merit of a system like WIS among users. A shared system makes it simpler to organize cooperation and structure information sharing between actors. However, the aforementioned lack of shared guidelines creates some uncertainty regarding when it is appropriate to create a new space. Two out of ten county administrative boards featured in this study reported that they have developed strategic routines (of which WIS is a part) for regional collaboration in crisis management. Additionally, there is considerable variety regarding to whom it falls to create a new space in WIS. Different county administrative boards described that it can be left to the single officer on duty, a collective decision by crisis management staff, or be bumped up the chain to the emergency preparedness director.

Although WIS is intended to facilitate crisis management in general, it is currently inappropriate for crises where rapid response is of the essence. Respondents report that in the face of sudden event, initiating a space in WIS is by no means the first point of order. Rather, the initial steps consist of alerting key personnel via telephone or emergency services. Only once these initial steps have been carried out do staff at the county administrative board (typically the officer or officers on duty) decide if it is necessary to create a space in WIS. In the affirmative, a space is typically created within the first hour after the initial report of a crisis. However, respondents also described that the ability to host shared spaces in WIS is well suited to slow-moving events such as the migrant crisis that lasted for several months and involved a wide variety of actors in the public- and private sector. However, extensive collaboration between actors and the separation of individual employee and functional role means that you cannot be sure who reads an update or piece of information. 
Table 2. Summary of analysis

\begin{tabular}{|c|c|c|c|}
\hline Domain & Congruence & Incongruence & Manifestation \\
\hline \multirow{4}{*}{$\begin{array}{l}\text { Nature of } \\
\text { Technology }\end{array}$} & & Characterization & $\begin{array}{l}\text { Promoters: Shifting definitions over time } \\
\text { Users: Multiple definitions across user base }\end{array}$ \\
\hline & Functionality & & $\begin{array}{l}\text { Promoters: Standardized, flexible environment that complements other } \\
\text { tools }\end{array}$ \\
\hline & & & $\begin{array}{l}\text { Users: System that supports logbooks and COPs with push- } \\
\text { notifications }\end{array}$ \\
\hline & & Openness & $\begin{array}{l}\text { Promoters: Centralized ownership of technology, shared ownership of } \\
\text { information } \\
\text { Users: Open or closed system - no differentiation between technology } \\
\text { and information }\end{array}$ \\
\hline \multirow{3}{*}{$\begin{array}{l}\text { Technology } \\
\text { Strategy }\end{array}$} & Scope & & $\begin{array}{l}\text { Promoters: Single system for civil emergencies } \\
\text { Users: Single channel for shared awareness }\end{array}$ \\
\hline & Task benefit & & $\begin{array}{l}\text { Promoters: Facilitate coordination and sharing between different } \\
\text { actors } \\
\text { Users: Supports creation and dissemination of COPs among a flexible } \\
\text { array of actors }\end{array}$ \\
\hline & User benefit & & $\begin{array}{l}\text { Promoters: Structured information management and task-person } \\
\text { separation } \\
\text { Users: Simplifies task transfer between staff and provides } \\
\text { comprehensive access to documentation }\end{array}$ \\
\hline \multirow{4}{*}{$\begin{array}{l}\text { Technology } \\
\text { in Use }\end{array}$} & & Initiating & $\begin{array}{l}\text { Promoters: Create space as soon as needed } \\
\text { Users: Contacting key personnel the top priority }\end{array}$ \\
\hline & Preparing & & $\begin{array}{l}\text { Promoters: Everyday usage encouraged to promote familiarity } \\
\text { Users: Lack of everyday usage a source of trivial problems }\end{array}$ \\
\hline & & Sharing & $\begin{array}{l}\text { Promoters: Extensive possibilities to monitor situations and anticipate } \\
\text { needs, encourages extensive sharing }\end{array}$ \\
\hline & & & $\begin{array}{l}\text { Users: Least capable actor sets the bar, restricts usage to basic features } \\
\text { Inability to anticipate audience restricts information to concise facts }\end{array}$ \\
\hline
\end{tabular}

Hence, users tend to stick to short, concise facts in order to minimize the risk of misinterpretation. Moreover, users are reluctant to engage in speculation or anticipate future requirements for the same reason.

While WIS does offer merit, staff at county administrative boards perceive an overall lack of interest from municipalities, and feel like they are doing most of the work. One employee voiced his frustration in that “...there's a feeling that we spend a lot of time and effort in informing external actors who in turn don't read [the material]. That causes us to lose motivation", adding that municipalities are often like "baby birds waiting to be fed" with information, and giving very little in return. The lack of interest does not have to be pervasive in order to have an impact. It is in the nature of crisis management and collaboration that all actors partake in the same information and receive the same updates, e.g. in the form of COPs. It is therefore ultimately the least knowledgeable user that determines how WIS can be used to collaborate and share information. Hence, although WIS houses advanced features (e.g. tools to create maps), it is far more common to create images or maps in external tools and add them as attachments.
This applies to COPs as well which are typically distributed as attached PDF-files or PowerPoint presentations.

Finally, a generally lukewarm interest also leads to users being less motivated to find ways of incorporating WIS into everyday work practices. This can in turn bring about trivial problems as one employee explains: "WIS isn't that hard to use, but you use it so very, very seldom. It's even to the point that...I'd say that the biggest obstacle is [remembering how to] log on to the system."

We identify three themes related to Technology in Use: initiating (how usage of the system is triggered), preparing (structures and routines set in place to support system use), and sharing (how resources are exchanged in the system).

\section{Analysis}

Table 2 summarizes the outcome of our analysis of the empirical findings in terms of frame congruence or incongruence. In keeping with Orlikowski and Gash [22], congruence is not synonymous with exact 
similarity, but rather compatibility. For instance, frames may be considered congruent if stakeholder groups highlight different, non-conflicting aspects of a technology, but will be considered incongruent if different conflicting views are presented. In addition, rather than consider the individual frame domains as homogeneous, we utilize the themes derived from the empirical findings to differentiate between aspects of each domain.

Our analysis reveals that the Technology Strategy frame exhibits strong congruence in that both stakeholder groups share a sense of the overall purpose of the system and its potential benefits for crisis management. Both groups highlight the value of WIS as a single, shared resource which supports the execution of key tasks in crisis management (e.g. reliable information sharing, coordination and documentation) as well as the separation of task and individual by moving away from personal e-mail accounts.

However, our analysis also reveals a large degree of incongruence in the Nature of Technology and Technology in Use frames. Concerning the former, both stakeholder groups offer compatible views on the functionality of WIS and that it offers a cohesive, flexible system for information storing and sharing between multiple actors across the public- and private sectors. However, both stakeholder groups exhibit shifting perspectives on the nature of WIS. The incongruence is discernible both within and across the two groups as users (i.e. county administrative boards) offer a range of different ways to describe WIS, whereas the promoters (i.e. MSB) have used different descriptions - and in doing so emphasized different features - over the past decade of the system's existence. Also, there are disparate views on the system's openness and the type of information that may be stored and/or shared. While the promoters of WIS (in both interviews and documentation) state categorically that MSB owns the system and provides technical support, they do not own or claim any responsibility for the information housed within. In contrast, users were generally unable to distinguish between system and information, and unsure of how access to information may be restricted to a limited range of actors.

The Technology in Use frame shows that both stakeholder groups share the view that in preparation for management of an actual crisis, everyday usage is important in order to promote familiarity with the system and ward off trivial user errors. Perspectives on the initiation of WIS usage (e.g. creating a space that can be shared between actors) diverged as the promoter-side (via documentation) had little to say on the topic beyond that a space should be promptly created by the actor that needs to reach out to other actors. Users, on the other hand, do not consider WIS a priority in the initial response to a crisis, instead emphasizing telephone or other direct means of communication. Further incongruence was found in the theme we refer to as sharing - i.e. how actors use WIS to manage and share information. Promoters (again, in both interviews and documentation) are keen to demonstrate the many ways in which WIS can support users in creating, managing and sharing information. Users, on the other hand, experience the grim reality that when sharing information across multiple actors, it is the least capable actor that determines the level of sophistication is system usage. Moreover, as the number of users grows, it also becomes more difficult to ascertain the expertise or level of experience of prospective participants. Hence, users have to engage in self-editorializing practices and be on guard for statements that can be misconstrued.

\section{Discussion}

The purpose of this paper is to study how ICTs are perceived to expedite information sharing and situational awareness in relation to crisis management. We have pursued this aim via a qualitative case study of WIS, a Web-based Information System developed for use in crisis management among local, regional and national government in Sweden.

\subsection{Implications for research}

WIS can be said to mimic a boundary object as it exhibits integrity yet flexibility in use [20] as it is shared by a wide variety of users, yet utilized in different ways depending on local preferences. This signifies different forms of organizational sensemaking [33] and perspective taking [17] vis-à-vis technology, illustrating how the ability to accommodate variety is "encouraged by communication systems that include an emphasis on supporting the distinctive needs of separate communities" [p. 358]. However, while WIS can span boundaries and support sensemaking, we argue that the issue of usability requires further attention. While WIS is a dedicated system for crisis management, we must also consider the issue of ICT-usability and being "ready-to-hand" [34]. Indeed, Landgren and Bergstrand [14] highlight that the technologies used in emergencies differ from the ones used in day-to-day operations. The idea of designing systems specifically for crises is common in the field of crisis informatics [e.g. 4, 5, 6], but this study demonstrates the limitations of such an approach. While the idea of having a system on standby, ready to be "unpacked" may be entirely feasible on a technical level, the lack of practice was an oft-stated concern in our study. As WIS is rarely used, we have to 
consciously focus on how to use the tool as much as what we want to accomplish, effectively forcing us to make sense of the tool as well as the situation. Hence, we see a greater need for research into how extant ICT can be leveraged to span the boundary between states of being (i.e. everyday life and crisis) as much as between stakeholder groups. A review by Reuter and Kufhold [2] demonstrates how the public can leverage platforms like Twitter, Facebook or wikis to share information and organize volunteers on very short notice. People are familiar with social media as they use it on a daily basis. In other words, we do not think about how to use social media, but rather do it unconsciously. We believe that this line of research can be informed by considering the affordances [35] of ICTs and how existing functionality and familiar services have been (retrospectively) and can be (prescriptively) deployed in the interest of crisis management.

\subsection{Implications for practice}

Our study of WIS suggests that it is perceived as an information warehouse [12] or conduit for communication [17]. While WIS does offer advanced features implemented in the software, few of these are actually beneficial as most users rely on other, external tools to create maps, compose documents et cetera. Furthermore, extant research emphasizes the importance of pre-event planning, e.g. in the form of action lists or emergency contacts to different agencies [36]. While county administrative boards are prepared for different contingencies, our study showed few if any of these preparations are facilitated by, or executed through, WIS. As very little of the functionality imbued in the system is actually used, it is more accurate to liken WIS to an infrastructure that connects actors rather than a tool. Wireless Emergency Alerts (WEA) recently tested by the Federal Emergency Management Agency (FEMA) [37] provide a good example of the infrastructure-perspective to crisis management. The system does not have any advanced features, but reaches virtually anyone with a smartphone in the USA. Hence, rather than seeking to build all-in-one systems for crisis management, practitioners should look closer into standardizing as little as possible (e.g. the communications channel), and build on that. The concept of Minimum Viable Product found in entrepreneurial literature [38] may provide inspiration in the endeavor to start small and gradually scale up.

\section{Conclusions}

Based on our study, we find that the two stakeholder groups, technology promoters and technology users, share a sense of the potential benefits of shared ICT resources in crisis management. However, the study also found that the two stakeholder groups have different views on several basic technical attributes as well as how the system should work in practice, including who bears responsibility for initiating use and its role in existing crisis management procedures.

The issue of timeliness provides a concrete illustration of the limitations of current use of ICT in crisis management. Our study showed that while the system in question, WIS, was useful in large-scale, slow-moving crises, it is often unwieldy to use in where rapid mobilization and deployment is important.

This study is based on a single case and thus cannot be said to comprehensively represent the current state of crisis management systems or practice around the world. However, single case qualitative studies do offer the potential for identifying and theorizing relevant aspects of ICT use [39], in this case the inherent difficulty in unpacking and deploying a specific resource for crisis management. Furthermore, this study is largely based on interviews that capture a snapshot in time. A longitudinal study of crisis information systems development and deployment, ideally involving firsthand observations, would offer more nuance and the ability to track the impact of each development as well as the interaction between system and procedure in greater detail.

\section{References}

[1] R. Perper, Deadly forest fires are burning across Greece this is where flames are scorching Europe, Retreived from https://nordic.businessinsider.com/photos-greece-europefires-2018-7? $\mathrm{r}=\mathrm{US} \& \mathrm{IR}=\mathrm{T}$, April $18^{\text {th }}, 2019$.

[2] C. Reuter, and M. A. Kaufhold,. "Fifteen years of social media in emergencies: a retrospective review and future directions for crisis informatics", Journal of Contingencies and Crisis Management, Vol. 26, No. 1, 2018, pp. 41-57.

[3] M. R. Endsley, "Measurement of situation awareness in dynamic systems", Human Factors, Vol. 37, No. 1, 1995, pp. 65-84.

[4] B. van de Walle, B. Brugghemans, and T. Comes, "Improving situation awareness in crisis response teams: An experimental analysis of enriched information and centralized coordination", International Journal of Human-Computer Studies, Vol. 95, 2016, pp. 66-79.

[5] M. Turoff, M. Chumer, B. V. de Walle, and X. Yao, "The design of a dynamic emergency response management information system (DERMIS)", Journal of Information Technology Theory and Application, Vol. 5, No. 4, 2004, pp. $1-35$.

[6] B. van de Walle, and M. Turoff, "Emergency Response Information Systems: Emerging trends and technologies", Communications of the ACM, Vol. 50, No. 3, 2007, pp. 29-31.

[7] R. Li, and A. Suh, "Factors influencing information credibility on social media platforms: Evidence from 
Face-book pages", Procedia Computer Science, Vol. 72, 2015, pp. 314-328.

[8] X. Lin, P. R. Spence, and K. A. Lachlan, "Social media and credibility indicators: The effect of influence cues", Computers in Human Behavior, Vol. 63, 2016, pp. 264271.

[9] S. Stieglitz, and L. Dang-Xuan, "Emotions and information diffusion in social media-sentiment of microblogs and sharing behavior", Journal of Management Information Systems, Vol. 29, No. 4, 2013, pp. 217-248.

[10] N. Bharosa, J. Lee, and M. Janssen,"Challenges and obstacles in sharing and coordinating information during multi-agency disaster response: Propositions from field exercises", Information Systems Frontiers, Vol. 12, No. 1, 2010, pp. 49-65.

[11] K. C. Kellogg, W. J. Orlikowski, and J. Yates, "Life in the trading zone: Structuring coordination across boundaries in postbureaucratic organizations." Organization Science, Vol. 17, No. 1, 2006, pp. 22-44.

[12] J. Wolbers, and K. Boersma, "The common operational picture as collective sensemaking", Journal of Contingencies and Crisis Management, Vol. 21, No. 4, 2013, pp. 186-199.

[13] L. K. Comfort, "Crisis management in hindsight: Cognition, communication, coordination, and control" Public Administration Review, Vol. 67, 2007, pp. 189197.

[14] J. Landgren, and F. Bergstrand, "Work Practice in Situation Rooms-An Ethnographic Study of Emergency Response Work in Governmental Organizations", in International Conference on Information Systems for Crisis Response and Management in Mediterranean Countries. P. Díaz, B. S. N. Bellamine, J. Dugdale and C. Hanachi, Eds., Springer, Cham, 2016, pp. 157-171.

[15] K. E. Weick, Sensemaking in organizations. Thousand Oaks, Sage Publications, 1995.

[16] I. Stigliani, and D. Ravasi, "Organizing thoughts and connecting brains: Material practices and the transition from individual to group-level prospective sensemaking", Academy of Management Journal, Vol. 55, No. 5, pp. 1232-1259.

[17] R. J. Boland Jr and R. V. Tenkasi, "Perspective making and perspective taking in communities of knowing" Organization Science, Vol. 6 No. 4, 1995, pp. 350-372.

[18] S. Kaplan, "Strategy and PowerPoint: An inquiry into the epistemic culture and machinery of strategy making", Organization Science, Vol. 22, No. 2, 2011, pp. 320-346.

[19] L. A. Suchman, "Representing practice in cognitive science", Human Studies, Vol. 11, No. 2-3, 1988, pp. 305325.

[20] P. R. Carlile, "A pragmatic view of knowledge and boundaries: Boundary objects in new product development" Organization Science, Vol. 13, No. 4, 2002, pp. 442-455.

[21] A. Lin, and L. Silva, "The social and political construction of technological frames", European Journal of Information Systems, Vol. 14, No. 1, 2005, pp. 49-59.

[22] W. J. Orlikowski, and D. C. Gash, "Technological frames: making sense of information technology in organizations", ACM Transactions on Information Systems, Vol. 12, No. 2, 1994, pp. 174-207.

[23] K. Olesen, "Implications of dominant technological frames over a longitudinal period", Information Systems Journal, Vol. 24, No. 3, 2014, pp. 207-228.

[24] E. Davidson, "A technological frames perspective on information technology and organizational change", The Journal of Applied Behavioral Science, Vol. 42, No. 1, 2006, pp. 23-39.

[25] R. K. Yin, Qualitative research from start to finish. New York, Guilford Press, 2011.

[26] S. Kaplan, "Framing contests: Strategy making under uncertainty”, Organization Science, Vol. 19, No. 5, 2008, pp. 729-752.

[27] R. K. Yin, Case study research: Design and methods, $3^{\text {rd }}$ Edition. Thousand Oaks, Sage publications, 2003.

[28] G. Walsham, "Interpretive case studies in IS research: Nature and method", European Journal of Information Systems, Vol. 4, No. 2, pp. 74-81.

[29] G. Walsham, "Doing interpretive research", European Journal of Information Systems, Vol. 15, No. 3, 2006, pp. 320-330.

[30] H. K. Klein, and M. D. Myers, "A Set of Principles for Conducting and Evaluating Interpretive Field Studies in Information Systems", MIS Quarterly, Vol. 23, No. 1, 1999, pp. 67-93.

[31] Miles, M. B., A. M. Huberman, and J. Saldaña, "Qualitative data analysis: An expanded sourcebook", $3^{\text {rd }}$ Edition. Thousand Oaks, Sage publications, 2014.

[32] W.J. Orlikowski, and J. J. Baroudi, "Studying information technology in organizations: Research approaches and assumptions", Information Systems Research, Vol. 2, No. 1, 1991, pp. 1-28.

[33] K. E. Weick, K. M. Sutcliffe, and D. Obstfeld, "Organizing and the process of sensemaking", Organization Science, Vol. 16, No. 4, 2006, pp. 409-421.

[34] P. M. Leonardi, "When flexible routines meet flexible technologies: Affordance, constraint, and the imbrication of human and material agencies", MIS Quarterly, Vol. 35, No. 1, 2011, pp. 147-167.

[35] I. Hutchby, "Technologies, texts and affordances", Sociology, Vol. 35, No. 2, 2001, pp. 441-456.

[36] M. W. Seeger, "Best practices in crisis communication: An expert panel process", Journal of Applied Communication Research, Vol. 34, No. 3, 2006, pp. 232244.

[37] FEMA, "The IPAWS National Test", Retrieved from https://www.fema.gov/emergency-alert-test. April 18th, 2019.

[38] D. R. Moogk, "Minimum viable product and the importance of experimentation in technology startups", Technology Innovation Management Review, Vol. 2, No. $3,2012$.

[39] A. S. Lee, and R. L. Baskerville, "Generalizing generalizability in information systems research", Information Systems Research, Vol. 14, No. 3, 2003, pp. 221-243. 